\title{
Time Course of Hemostatic Disruptions After Traumatic Brain Injury: A Systematic Review of the Literature
}

\author{
Alexander Fletcher-Sandersjöö ${ }^{1,2^{*}}$ (D) Eric Peter Thelinn ${ }^{2,3}$, Marc Maegele $^{4,5}$, Mikael Svensson 1,2 \\ and Bo-Michael Bellander ${ }^{1,2}$ \\ (c) 2020 The Author(s)
}

\begin{abstract}
Almost two-thirds of patients with severe traumatic brain injury (TBI) develop some form of hemostatic disturbance, which contributes to poor outcome. While the initial head injury often leads to impaired clot formation, TBI is also associated with an increased risk of thrombosis. Most likely there is a progression from early bleeding to a later prothrombotic state. In this paper, we systematically review the literature on the time course of hemostatic disruptions following TBI. A MEDLINE search was performed for TBI studies reporting the trajectory of hemostatic assays over time. The search yielded 5,049 articles, of which 4,910 were excluded following duplicate removal as well as title and abstract review. Full-text assessment of the remaining articles yielded 33 studies that were included in the final review. We found that the first hours after TBI are characterized by coagulation cascade dysfunction and hyperfibrinolysis, both of which likely contribute to lesion progression. This is then followed by platelet dysfunction and decreased platelet count, the clinical implication of which remains unclear. Later, a poorly defined prothrombotic state emerges, partly due to fibrinolysis shutdown and hyperactive platelets. In the clinical setting, early administration of the antifibrinolytic agent tranexamic acid has proved effective in reducing head-injury-related mortality in a subgroup of TBI patients. Further studies evaluating the time course of hemostatic disruptions after TBI are warranted in order to identify windows of opportunity for potential treatment options.
\end{abstract}

Keywords: Traumatic brain injury, Hemostasis, Coagulation, Coagulopathy, Thrombosis

\section{Background}

Despite improvements in medical triage and tertiary care, traumatic brain injury (TBI) is associated with significant morbidity and mortality [1]. The initial injury is often followed by hemostatic disturbance, which is present in up to two-thirds of patients with severe TBI and associated with increased mortality $[2,3]$. While it is still unclear exactly how TBI affects the coagulation system, the primary drivers appear to be platelet dysfunction,

\footnotetext{
*Correspondence: alexander.fletcher-sandersjoo@ki.se

${ }^{1}$ Department of Neurosurgery, Karolinska University Hospital, Stockholm, Sweden

Full list of author information is available at the end of the article
}

endothelial activation, disturbed fibrinolysis, endogenous anticoagulation, and inflammation [2, 4-6].

There is controversy regarding the exact nature of hemostatic disruption after TBI, and evidence exists to support the presence of both a hyper- and hypocoagulable state [2]. While the initial head injury often leads to impaired clot formation and exacerbation of hemorrhagic lesions [2, 7-9], TBI is also independently associated with an increased risk of venous thromboembolism [10-13] and ischemic stroke [14-18]. Most likely, there is a progression from early increased bleeding risk to a later prothrombotic state. However, an overlap and lack of distinction between the phases exists. 
In this paper, we systematically review the literature on the time course of hemostatic disruptions following TBI, as reflected by temporal changes in selected laboratory assays, in order to highlight current evidence and potential future directions.

\section{Methods}

\section{Search Strategy and Selection Criteria}

A search strategy was decided upon (Supplementary file 1) and carried out using the MEDLINE database from its date of inception until December 2019. Titles and abstracts were independently screened to determine whether they met the inclusion criteria. Full texts of the chosen articles were assessed to confirm this. Reference lists of relevant articles were screened for additional studies.

\section{Inclusion and Exclusion Criteria}

Studies of adult and pediatric TBI patients that reported the time course ( $>1$ sample per patient) of one or several hemostatic assays were eligible for inclusion. The assays of primary interest were platelet count, prothrombin time (PT), partial thromboplastin time (PTT), activated partial thromboplastin time (APTT), D-dimer, thrombin antithrombin III complex (TAT), Prothrombin fragment $1+2(\mathrm{~F} 1+2)$, tissue plasminogen activator (t-PA), plasminogen activator inhibitor-1 (PAI-1), thromboelastography (TEG), thromboelastometry (TEM), Multiplate ${ }^{\circledR}$ (Roche Diagnostics, Basel, Switzerland) and VerifyNow ${ }^{\circledR}$ (Accumetrics, San Diego, CA, USA). There were no restrictions on methodological quality. Studies were excluded if they were non-English, and if it wasn't possible to interpret data relating to patients with TBI (e.g. multitrauma studies without a subgroup analysis) or a specific laboratory assay (e.g. studies that grouped several assays together as one). For studies evaluating the effect of a hemostatic intervention, only data for the control group were extracted.

\section{Data Abstraction}

Using a customized form, we extracted data from the included studies and stored them in an electronic database. Where applicable, the following data were abstracted: study design, patient ages, cohort size, TBI severity, presence of extracranial injuries, pre-injury antithrombotic or anticoagulation medication, sampling times, time from injury to first sample, and the temporal trajectory for each assay. No meta-analysis was possible due to the heterogeneity of the data.

\section{Results}

\section{Study Selection and Characteristics}

The initial literature search generated 5,049 articles, of which 4,910 were excluded following duplicate removal as well as title and abstract review. Full-text assessment of the remaining 139 articles yielded 33 studies that were included in the final review (Fig. 1).

\section{Platelets}

\section{Platelet Count}

We included 17 studies with platelet count data, of which all but one found that platelet count decreased after injury [19-34]. In the largest study of 274 adults with severe TBI, mean platelet count was normal on admission and then decreased over time, with a steeper decline in more severe cases [20]. A similar pattern of posttraumatic decrease in platelet count was seen in the prospective studies [22, 23, 28] as well as in mild TBI [32]. Most often the platelet counts remained within reference ranges $[19$, $20,24-26,29,30,35]$, but some studies reported on the development of posttraumatic thrombocytopenia as well

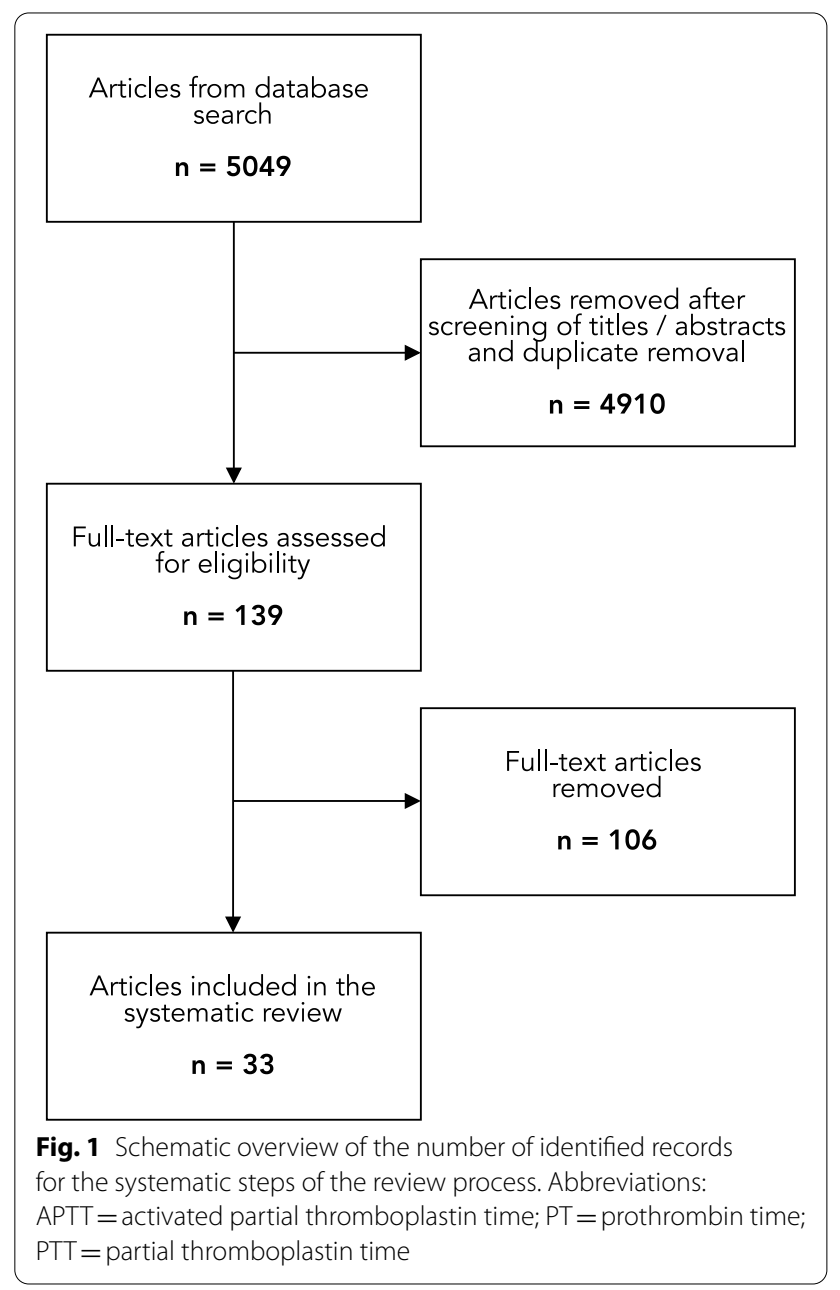


$[21,27,28,32]$. The lowest platelet count levels were seen 1-5 days after injury [27-32], followed by a rebound to admission levels by day $5-9[28,30,31]$. One study found no change in platelet count over time, but only sampled blood tests on admission and 10-17 days after injury [35] (Table 1).

\section{Platelet Function}

We included 6 studies with platelet function data. The methods used were TEG, Multiplate ${ }^{\circledR}$ (Roche Diagnostics, Basel, Switzerland) and spectrophotometry. All studies found that platelet function decreased after injury $[22,24,29,36-38]$. This appeared to be independent of platelet transfusion and pre-injury antithrombic therapy $[36,37]$. In the largest prospective study of 153 adults with TBI, mean adenosine diphosphate (ADP)-induced aggregation was below-normal on admission and continued to decrease during the first $24 \mathrm{~h}$ after injury [36]. Five other studies reported a similar pattern of normal to below-normal platelet function on admission that then decreased over time in stimulation to collagen (COL) [24], ADP, thrombin receptor activating peptide (TRAP) and arachidonic acid (AA or ASPI) [22, 37]. The lowest platelet function levels were observed 6-48 h after injury [24, 29,37,38] and then returned to normal after 2-16 days [22, 29, 37, 38]. In the two studies that observed patients for more than one week, platelet function increased to above-normal levels (i.e. hyperactive platelets) following their initial decline [29, 37] (Table 2).

\section{Coagulation Cascade PT, PTT and APTT}

We included 12 studies with PT, PTT and/or APTT data. Most of these studies noted that TBI was followed by a decrease in markers of coagulation cascade function [19, $21,32,33,39,40]$. In the largest study of 441 patients with isolated TBI, mean APTT was increased during the first $12 \mathrm{~h}$ after injury, with a mean value of $16 \mathrm{~s}$ (reference range: 10.3-13.4 s) [39]. A similar pattern, although within reference ranges, was seen in another study of 234 adult severe TBI patients, where APTT and INR significantly increased during the first $3 \mathrm{~h}$ after injury, reaching median values of $29.2 \mathrm{~s}$ (reference range: $24-36 \mathrm{~s}$ ) and 1.07 (reference range: 0.8-1.2), respectively [19]. These observations were further supported by three smaller studies that all identified posttraumatic abnormally increased PT, INR and PTT that peaked at 2-6 h after injury [21,33,40]. In addition, one study found that Glasgow Coma Scale (GCS) was inversely proportional to $\mathrm{PT}$, indicating that severer TBI cases induce a more pronounced coagulation cascade dysfunction [40]. Following the initial phase, values then seemed to return to normal after $12 \mathrm{~h}$ to several days following injury [32, 33, 40].
Two studies saw no significant change in these coagulation cascade assays over time [23, 25] (Table 3).

\section{TAT and $\mathrm{F} 1+2$}

We included 5 studies with TAT and/or F1 +2 data. All of these studies found that TAT and F1 +2 were elevated during the first day of injury [26, 27, 41-43]. In the largest study, which included 28 patients with isolated TBI, mean TAT was elevated on admission (mean $8.6 \mathrm{~h}$ after injury) and then decreased to reference levels after 5 days [27]. The other studies reported a similar pattern of increased TAT and/or F1 +2 levels on admission that then decreased, reaching reference ranges from $24 \mathrm{~h}$ up to one week after injury [26, 41-43] (Table 4).

\section{Fibrinolysis \\ $D$-dimer}

We included 11 studies with D-dimer data, all of which reported increased levels after injury [19, 23, 26, 27, 33, $35,40,41,43-47]$. In the largest prospective study of 141 patients with isolated TBI, mean D-dimer was increased on admission with mean peak levels of $8 \mu \mathrm{g} / \mathrm{mL}$ (normal range: $0.0-1.0 \mu \mathrm{g} / \mathrm{mL}$ ) observed $6 \mathrm{~h}$ after trauma. This was then followed by a decrease over time [23]. Another study of 234 TBI patients identified a D-dimer peak within $3 \mathrm{~h}$ of injury in patients with head abbreviated injury scale (AIS) 5 , and within 3-6 h in those with head AIS 4 [19], where median levels reached as high as $45.3 \mu \mathrm{g} / \mathrm{mL}$. In these studies, D-dimer levels were also correlated with injury severity $[19,40]$ and hemorrhage progression [23]. A similar pattern of posttraumatic increase in D-dimer was seen in several other smaller studies as well [26, 27, 33, 35, 40,41,43-47]. In respect of time to normalization, most studies were limited by short follow-up time [19, 23, 26, 33, 40,41,46, 47], but one reported that $55 \%$ of patients normalized their D-dimer levels within 3 days of injury [40] (Table 5).

\section{PAl-1 and t-PA}

We included 4 studies with PAI-1 and/or t-PA data. In the study of 141 TBI patients by Fair et al., PAI- 1 and t-PA were elevated on admission and then decreased over time [23]. A similar pattern of posttraumatic increase in PAI-1 and t-PA, with the highest levels seen on admission, was observed in the other three smaller studies as well $[43,46,48]$ (Table 6).

\section{Viscoelastic Assays}

We included 5 studies with viscoelastic assay data. In a study of 91 pediatric patients with severe TBI, elevated TEG clot lysis (LY30) was noted within the first hour and decreased over time [49]. In another study by the same group, where early sampling was not performed, 


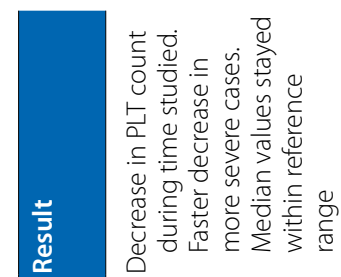

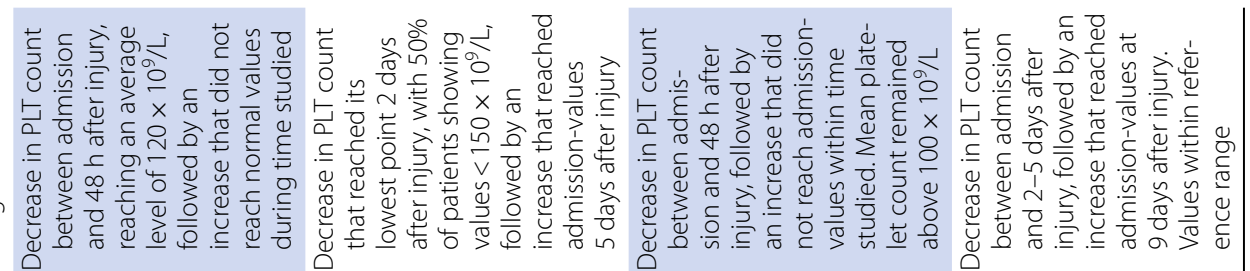

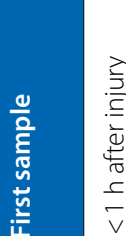

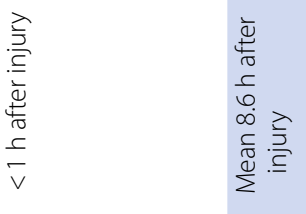

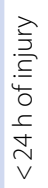

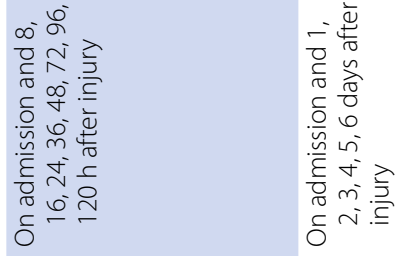

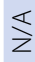

$\$$

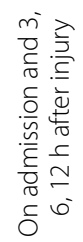

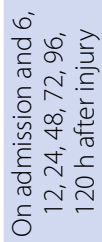

文

0
0
0
0
0

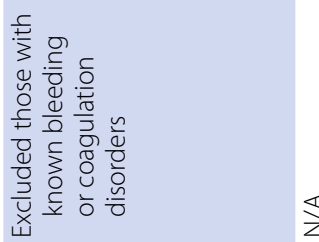

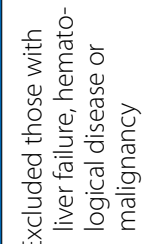

.

$\sigma$

ิㅗำ

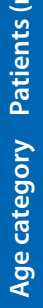

文

㐫

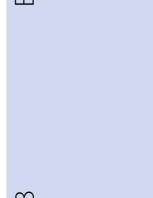

$\frac{\pi}{z}$

$\stackrel{\infty}{\sim}$

구

ชิ

$\stackrel{+}{m}$

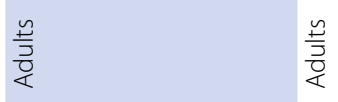

$\frac{\longleftarrow}{z}$

$\frac{\pi}{z}$

을

要等产

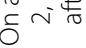
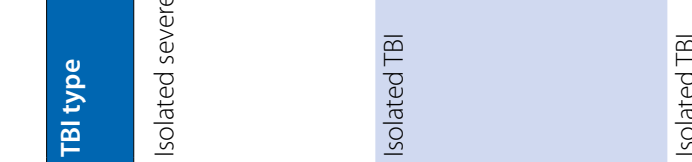

$\bar{p}$
$\frac{\hat{\theta}}{0}$
$\frac{0}{0}$
$\underline{0}$

$\$$

$\$$

$\bar{\oplus}$
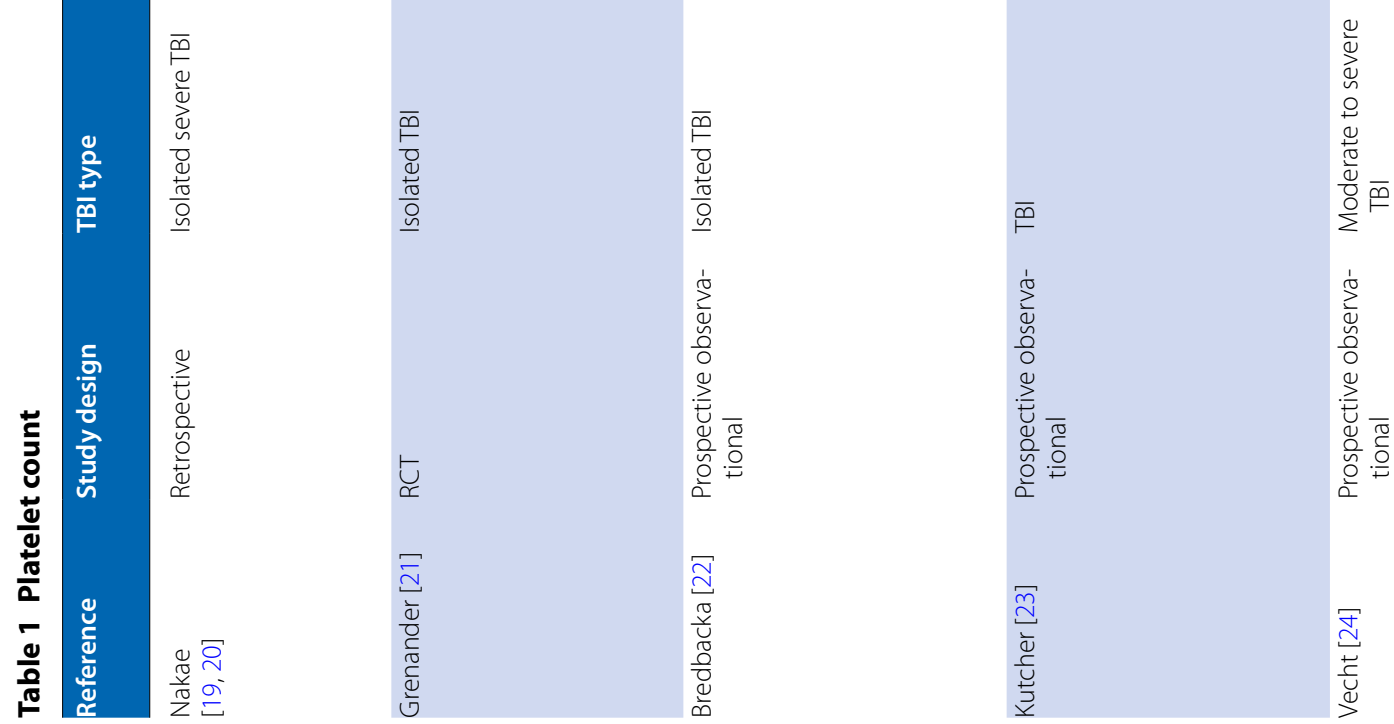

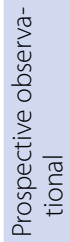

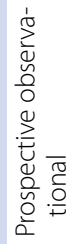

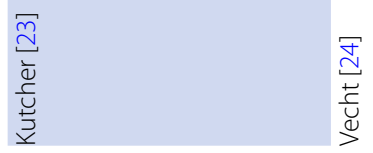




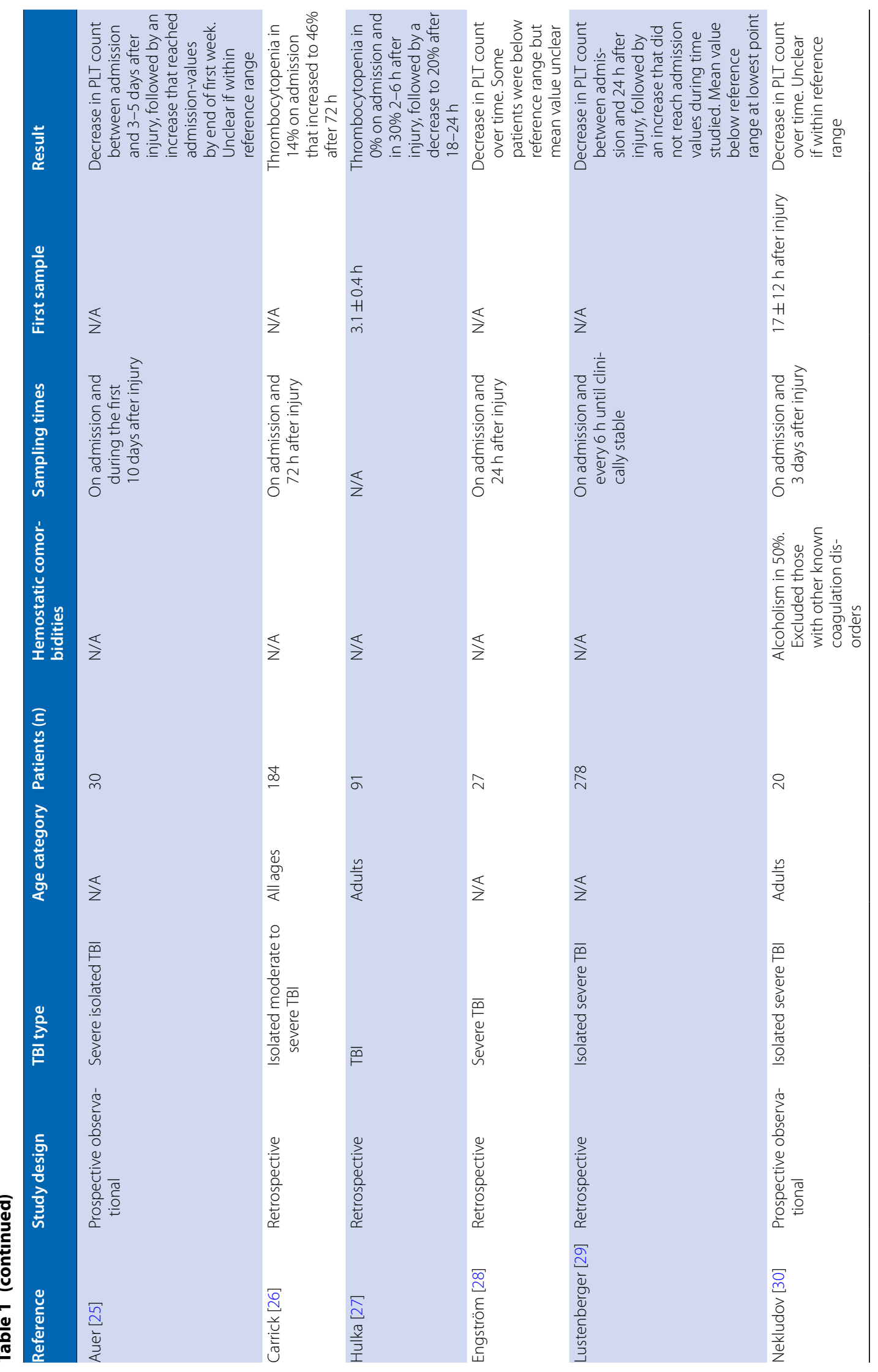



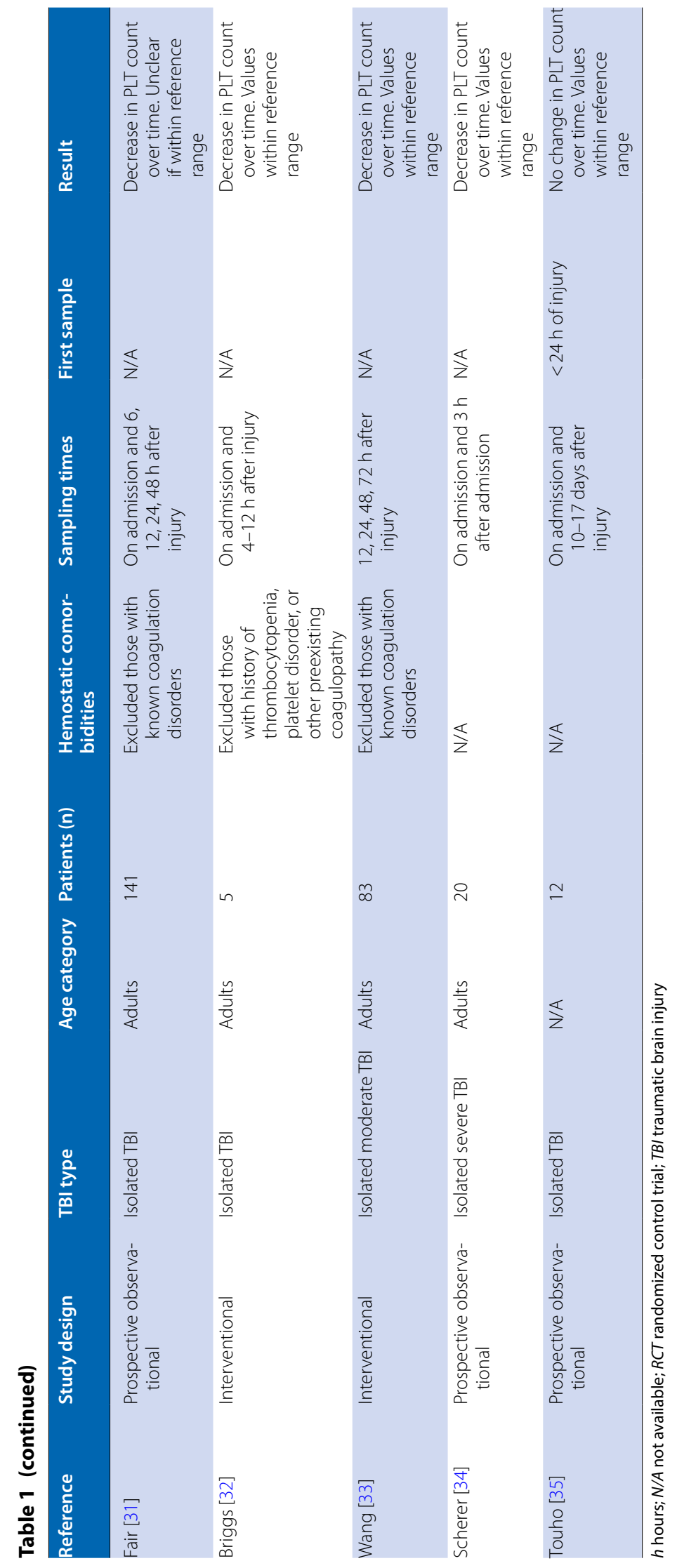


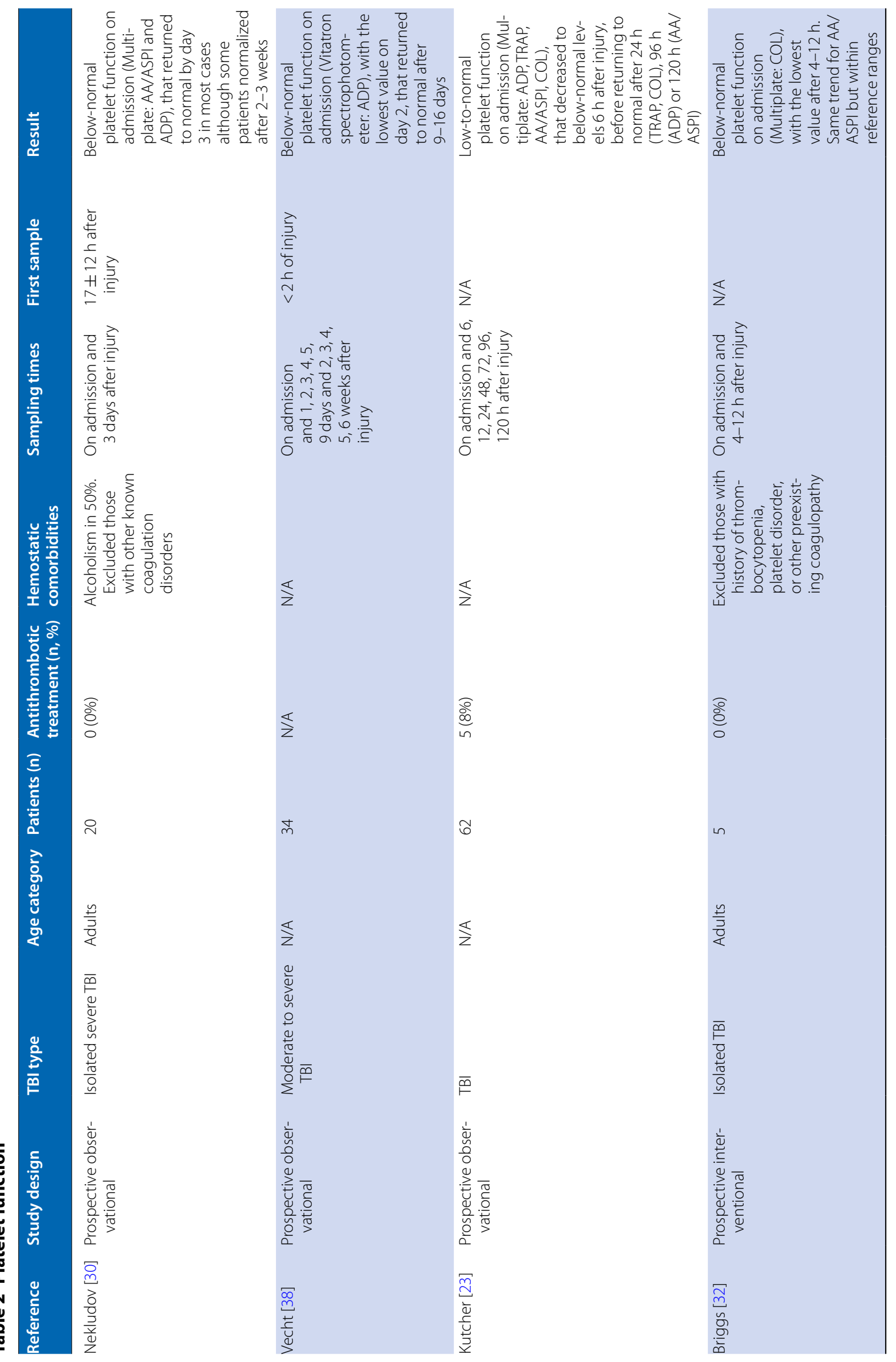




$$
\|
$$




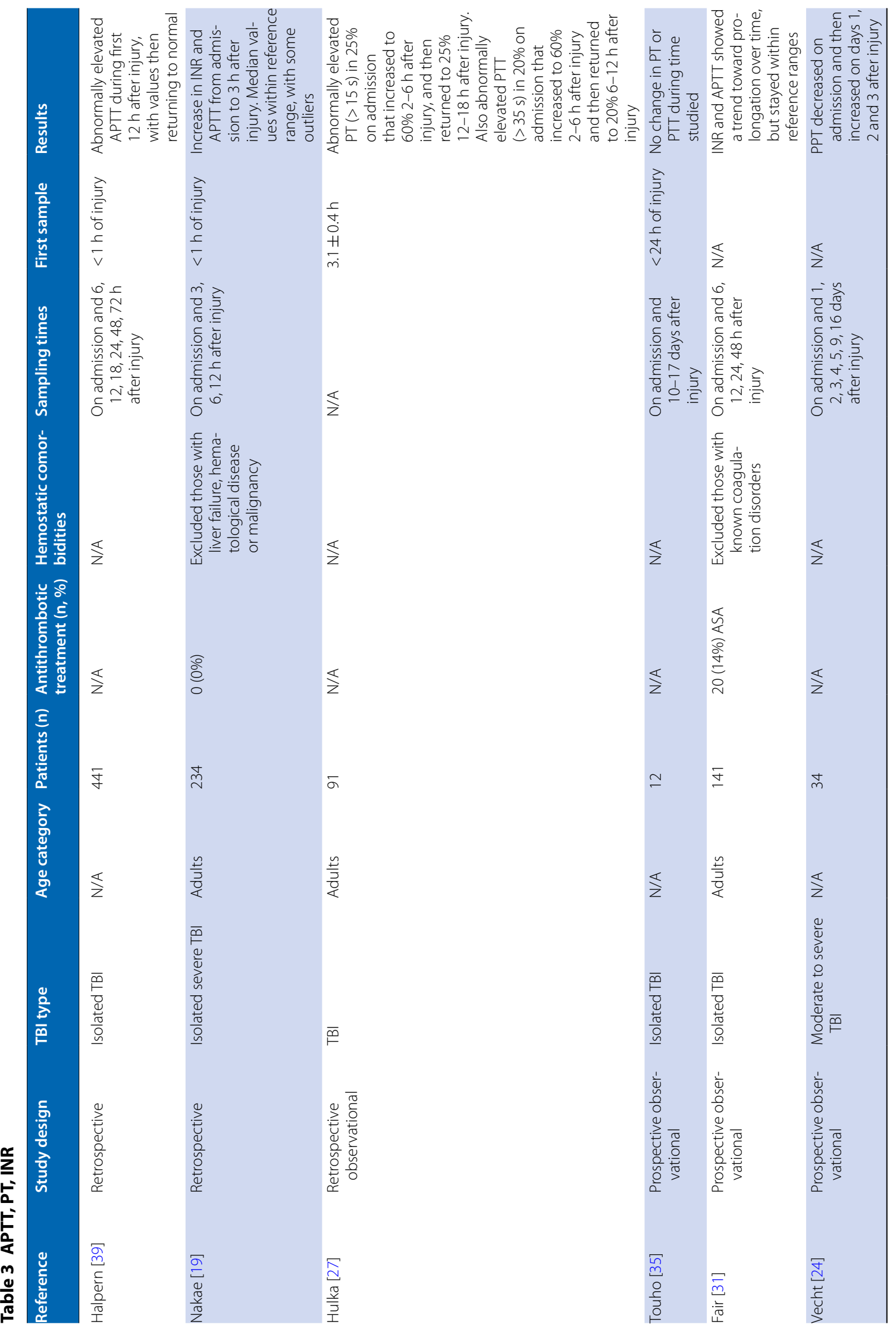




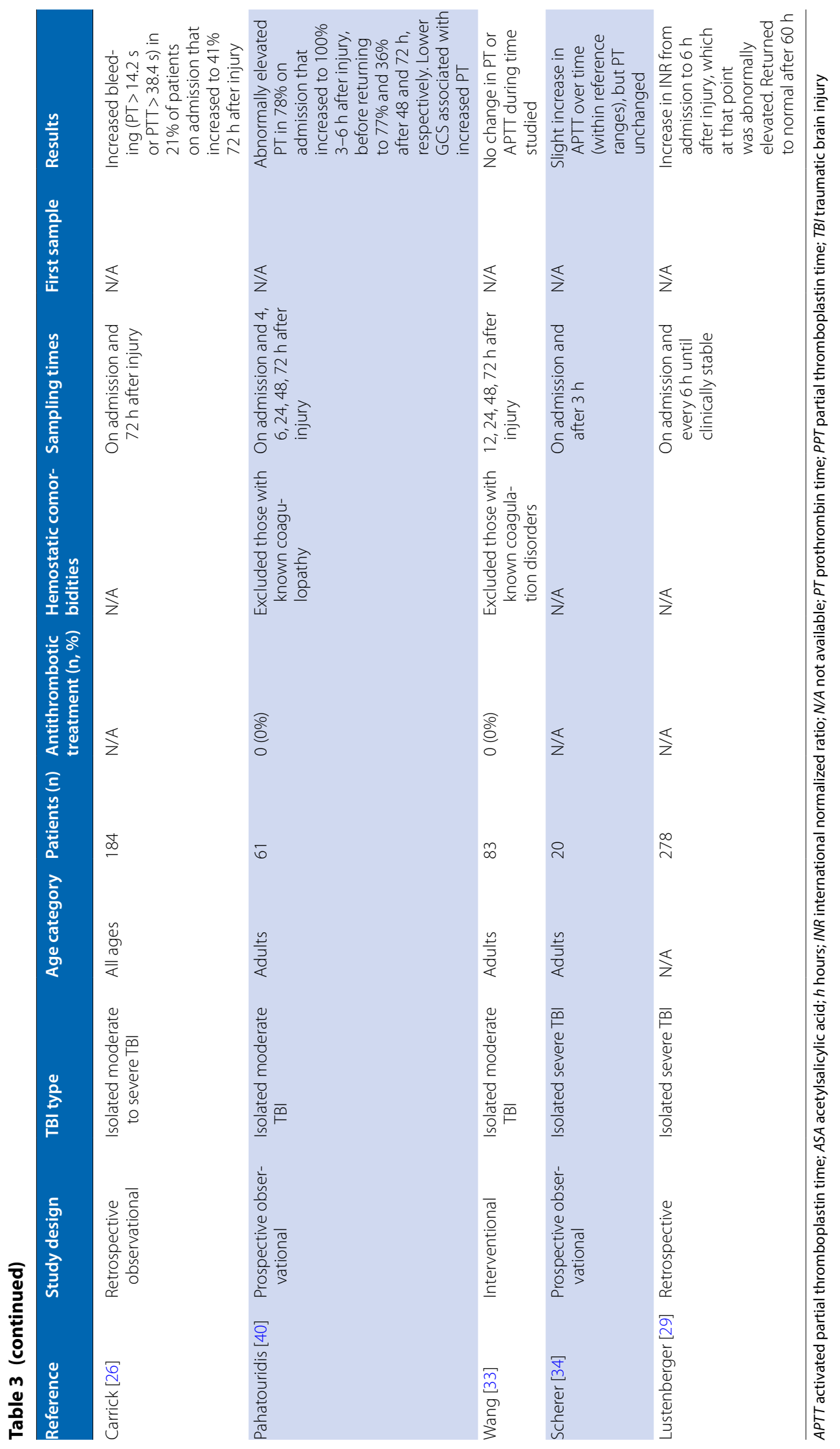




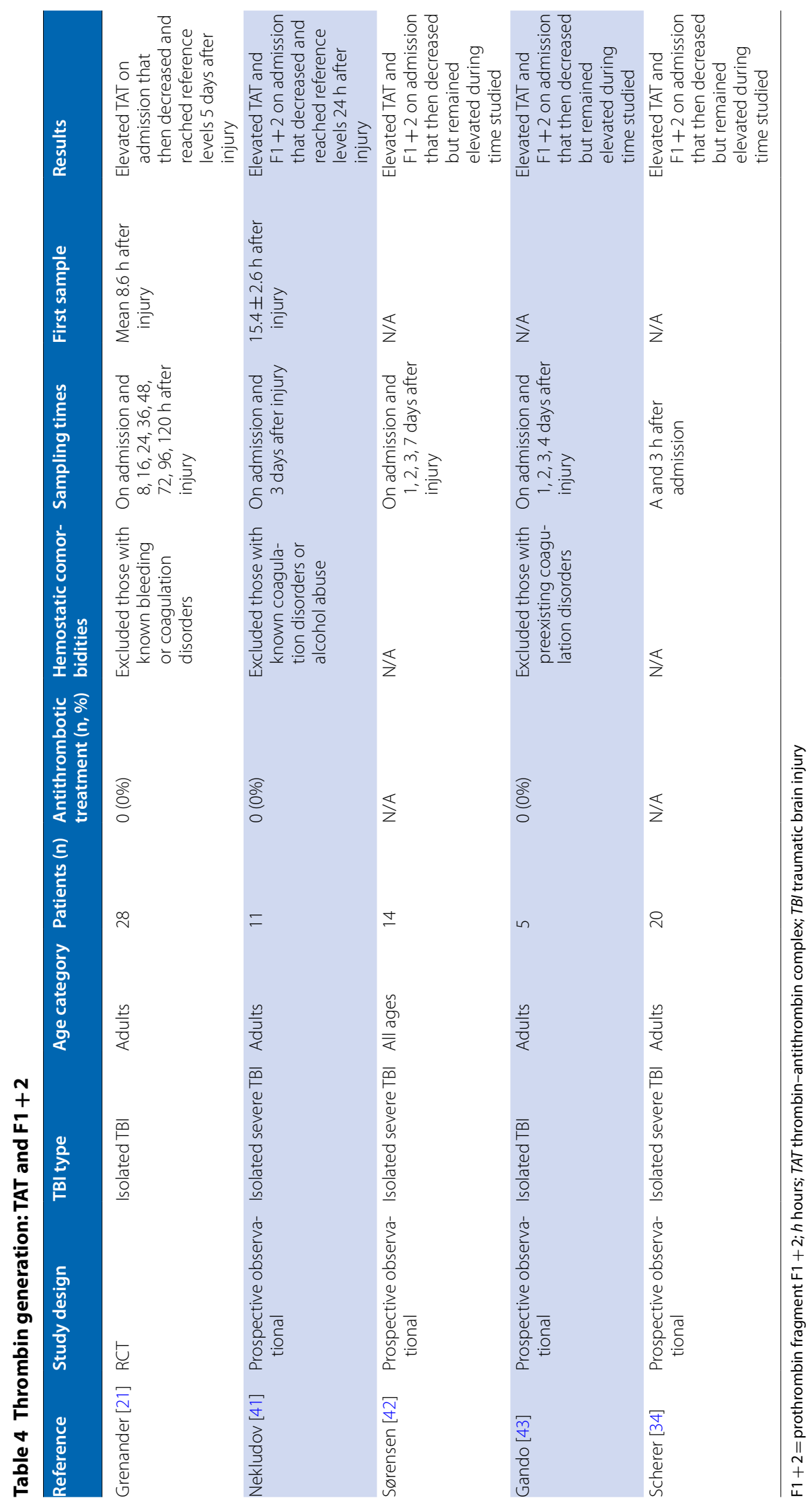




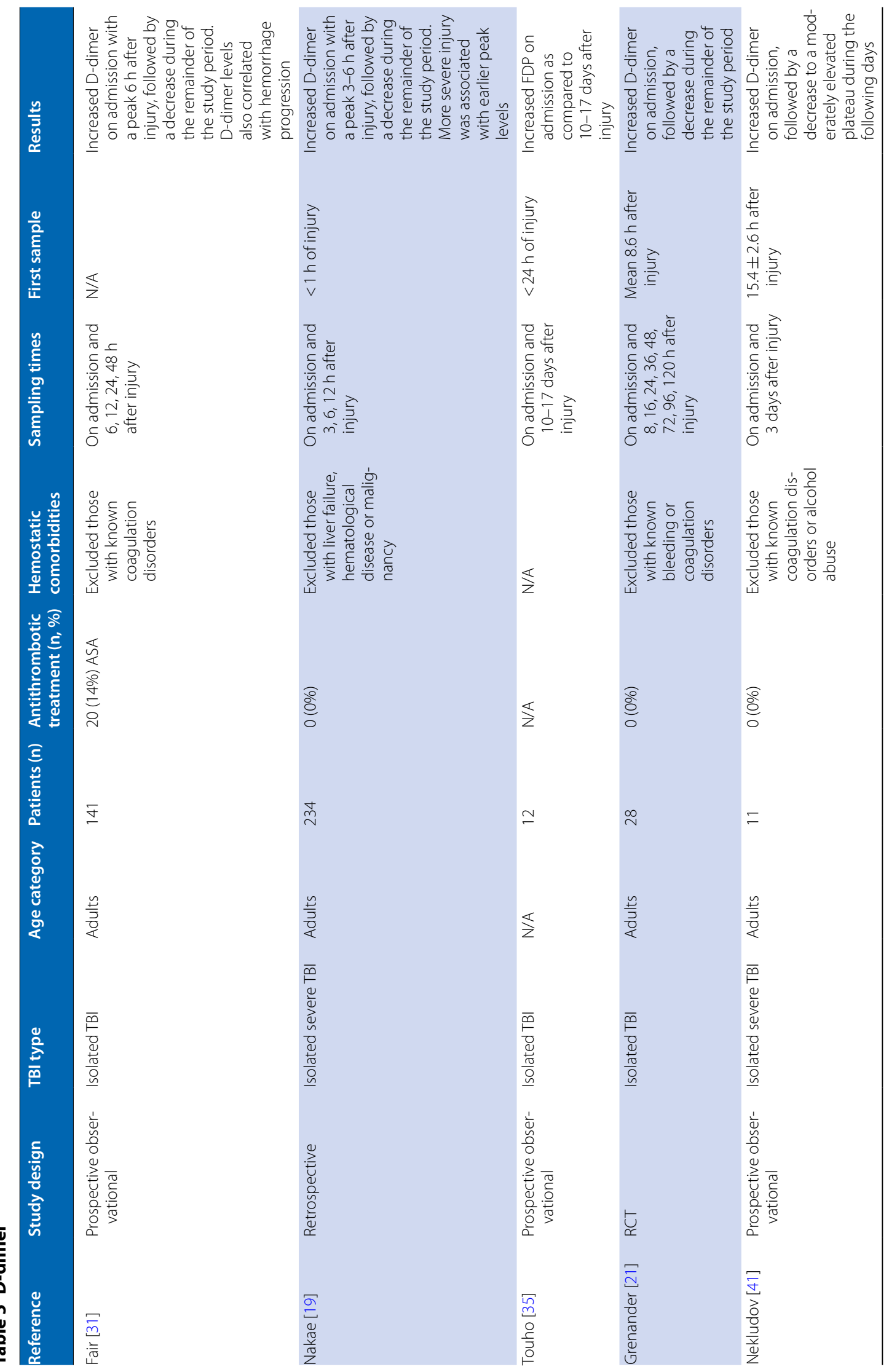




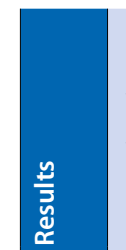

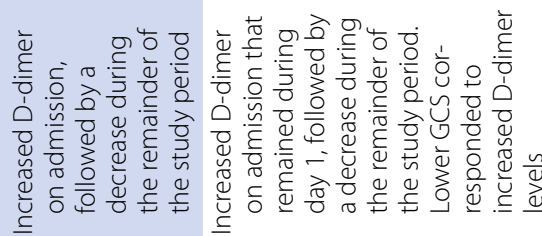

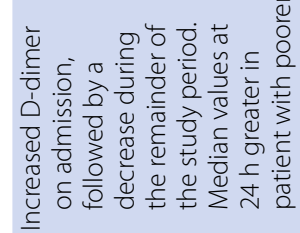
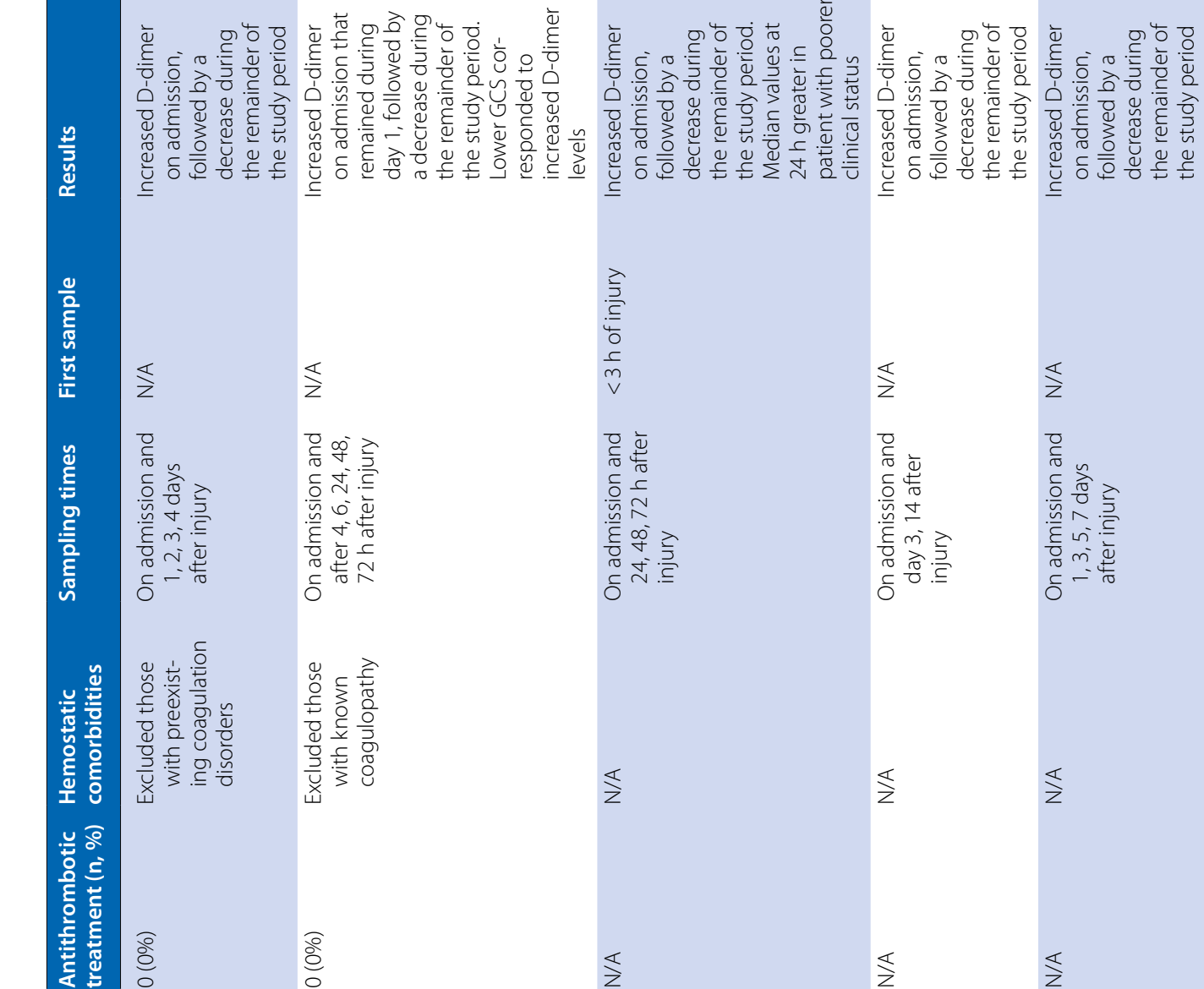

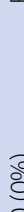

oे

$\frac{o}{0}$

$\frac{\$}{z}$

$\stackrel{\longleftarrow}{\Sigma}$

$\stackrel{\longleftarrow}{\Sigma}$

$\stackrel{\longleftarrow}{z}$

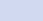
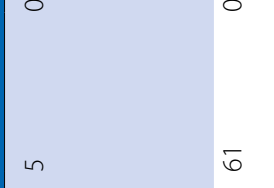

$\overline{0}$

ㅎํㄹำ

वั

$\frac{\frac{n}{5}}{\frac{7}{4}}$

$\frac{\sqrt{5}}{\frac{5}{4}}$

z

†

$\frac{\sqrt{5}}{\frac{5}{0}}$

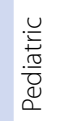

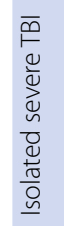

है
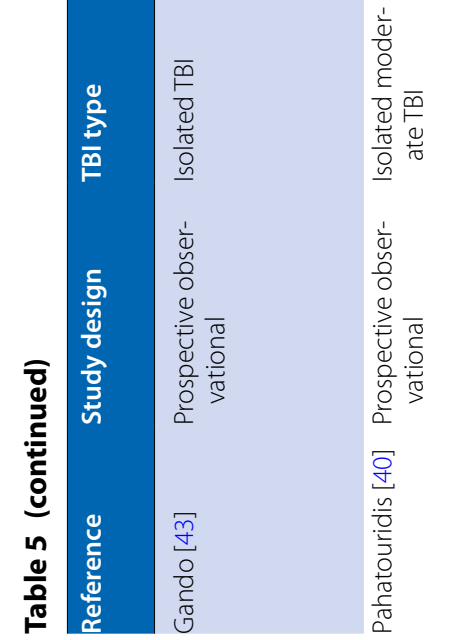

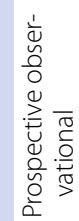

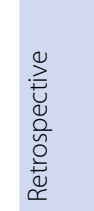

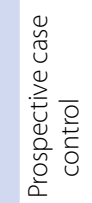

J
$\frac{\mathbb{J}}{N}$
$\frac{0}{4}$
$\frac{0}{4}$

$\$$

$\overline{0}$
$\frac{0}{0}$
0
0
0
$\frac{0}{0}$
0
0

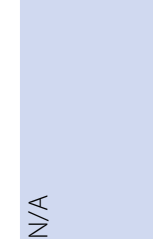




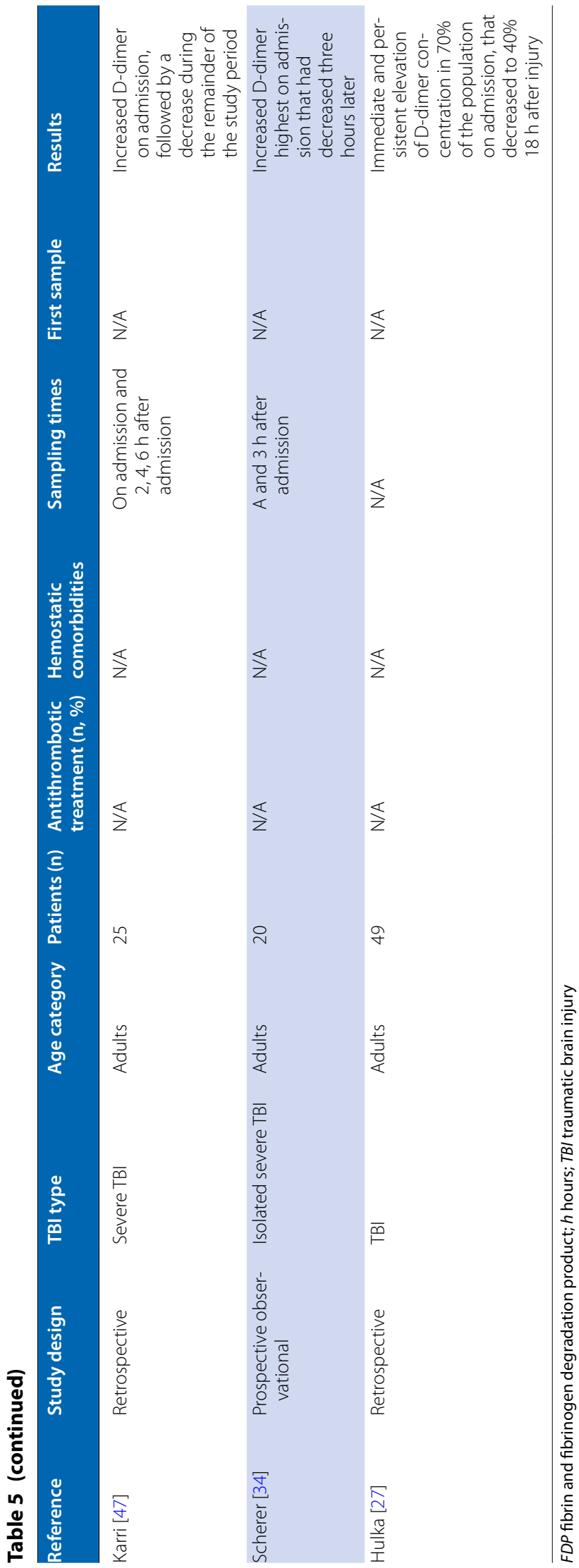

no significant change in TEG LY30 was detected. Similarly, in samples taken regularly during the first two days after trauma, Fair et al. found no significant change in TEG LY30, although it is unclear when the first sample was taken [23]. Another ROTEM study of 83 adults with isolated mild TBI, where blood sampling was performed 12-72 h after injury, found no significant change in clotting time (CT), clot formation time (CFT) or maximum clot firmness (MCF). Following the initial phase, two pediatric studies from the same center observed that TEG LY30 then decreased below reference ranges, indicative of fibrinolysis shutdown. In the first study, where sampling was performed on admission and once daily, fibrinolysis shutdown was the most common phenotype between postinjury day 1 and continuing through postinjury day 3 [50]. In the follow-up study, in which early sampling was performed with a higher frequency, fibrinolysis shutdown was the most dominant phenotype already $3 \mathrm{~h}$ after trauma [49] (Table 7).

\section{Discussion}

TBI is often followed by hemostatic disturbance [2, 3], which has been associated with worse clinical outcome [51]. It is important to note that hemorrhagic lesion progression primarily occurs during the first hours after injury, with one study of mild TBI reporting that lesion progression had stopped in $75 \%$ of patients within $2 \mathrm{~h}$, and in $97 \%$ within $24 \mathrm{~h}$, of injury [52]. This highlights the window of opportunity for the treatment of deranged hemostasis. The aim of this study was to review the literature on the time course of hemostatic disruptions following TBI. Thirty-three studies were included, contributing data on temporal changes in primary hemostasis, coagulation cascade function and fibrinolysis. To the best of our knowledge, this is the first review of its kind and contributes findings that are important for patient management and future study design.

\section{Primary Hemostasis}

Clinically, primary hemostasis is assessed by platelet count and platelet function [53]. In this review, we observed that TBI was followed by a decrease in platelet count and function that appeared to be independent of platelet transfusions and antithrombic therapy $[36,37]$. Platelet count typically stayed within reference ranges [19, 20, 24-26, 29, 30,35] and returned to admission levels within two weeks $[28,30,31]$, while platelet function decreased below reference levels about 6-48 h after injury [24, 29, 37, 38]. The reason behind this is likely multifactorial. Consumption of platelet-fibrin clot formation probably decreases platelet count early on, a decrease which is aggravated by dilution due to extensive fluid resuscitation therapy. Additional decreases 


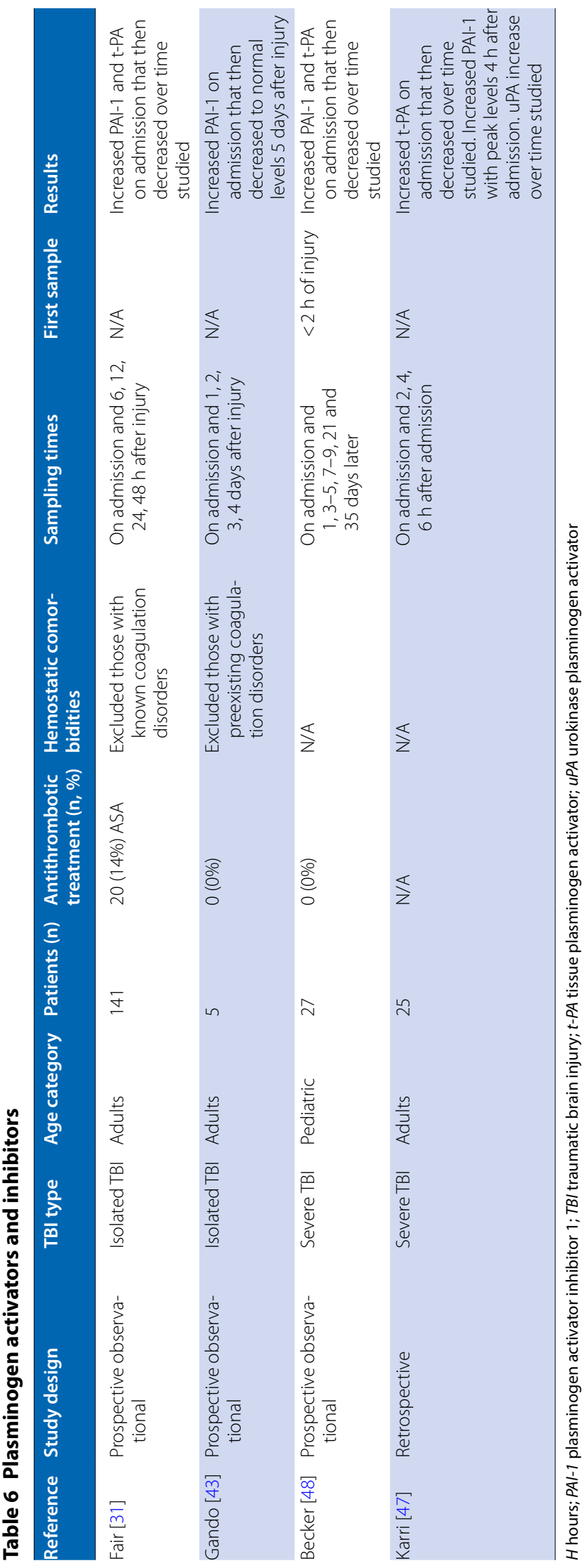


in platelet count and function may be the result of consumptive depletion and exhaustion [2]. Platelet dysfunction could also be driven by endothelial injury [54], with endothelial disruption catalyzing systemic activation of platelets that renders them inert to subsequent stimulation [55], as well as factors within soluble plasma that render platelets inactive after trauma [56]. Platelets also undergo structural change following trauma, which could decrease their function, but it remains unclear whether this process occurs in isolated TBI [55].

Two studies also found that platelets became hyperactive following their initial dysfunction [29, 37]. This was supported by a TEG study that noted increasing maximum amplitude (MA) levels 7 days after TBI [57] (MA represents clot strength that is mainly dependent on platelet function). Platelet hyperactivity could explain the increased risk of thrombosis seen in TBI patients [10-18, 58], but future studies are warranted to assess its clinical significance.

In summary, platelet dysfunction and decreased platelet count were evident during the acute postinjury phase. In patients surviving the initial insult, platelets became hyperactive, although the exact time frame remains to be determined (Fig. 2).

\section{Clinical Implications}

Platelet dysfunction was seen between six hours to several days after injury. Considering the fact that lesion progression is most prevalent within the first hours of trauma [52], this might imply that platelet alterations are not a main cause behind exacerbation of hemorrhagic lesions in TBI. This is supported by the fact that posttraumatic platelet dysfunction has not been associated with intracranial lesion progression [37]. However, while hemorrhagic expansion of the primary brain contusions is a chief concern, delayed noncontiguous hemorrhagic lesions at remote locations may also appear in the evolution of a patient's clinical course [59]. This could be caused by platelet dysfunction. Further adding to the uncertainty regarding the clinical significance of platelet dysfunction in TBI, platelet function assays were originally designed to detect antiplatelet medication efficacy, and have secondarily been extrapolated to trauma, making interpretation of cutoff values unclear. The assays are also limited by the absence of endothelium and flow conditions, as well as variability related to platelet count and hematocrit level [54]. Highlighting this, studies of platelet function-targeted therapy have failed to demonstrate clinical efficacy. While there is some evidence that platelet transfusion can correct platelet dysfunction in TBI [60], others studies suggest that transfusions are more likely to improve aspirin-induced, rather than trauma-induced, dysfunction [24]. Desmopressin could be an alternative to platelet transfusions, though there exist only mixed results from low-quality studies [61, 62]. Thus, it is unclear whether posttraumatic platelet dysfunction contributes to lesion progression in TBI, and there is also no proven treatment for TBI-induced platelet dysfunction.

\section{Coagulation Cascade}

In the clinical setting, coagulation cascade function is assessed by PT, PTT and APTT, as well as surrogate markers of thrombin generation such as TAT and F1 +2 . We observed that TBI was followed by a temporary increase in APTT, PTT and PT [19, 21, 33, 39, 40], indicating decreased coagulation cascade function. This seemed to be apparent on admission and was most pronounced during the first hours after injury $[19,21,33$, 40]. TAT and F1 +2 were also elevated during this time [26, 27, 41-43], indicating that the coagulation cascade dysfunction was secondary to increased thrombin generation. Therefore, the changes are probably the result of consumption, where excess clotting leads to depletion and/or dysfunction of coagulation factors in plasma [39]. Many believe that this is due to trauma-induced unregulated tissue factor release [58, 63], which would stimulate thrombin generation and consumption of clotting factors in the ways observed in this review, but evidence remains elusive. Thus, the first few hours following TBI are characterized by coagulation cascade dysfunction that is likely secondary to unregulated thrombin production (Fig. 2).

\section{Clinical Implications}

Coagulation cascade dysfunction appears to occur when the risk of intracranial lesion progression is high [52], supporting a theory that it contributes to hemorrhagic expansion in TBI. This presents a possible window of opportunity for interventions. In general trauma, there has been much interest in the use of fresh frozen plasma (FFP), which contains both fibrinogen and clotting factors [64], to limit blood loss [2]. In isolated TBI, retrospective evidence has found that early plasma transfusion is associated with improved survival in patients with multifocal intracranial hemorrhage [65], but no randomized controlled trials have been performed to validate this. Prothrombin complex concentrate (PCC) provides another theoretical treatment strategy for coagulation cascade dysfunction secondary to consumption of clotting factors, and is currently recommended for the emergency reversal of vitamin $\mathrm{K}$ anticoagulant therapy in TBI [2]. One retrospective study of general trauma patients found that PCC decreased mean INR in patients without warfarin treatment [66], but there is currently no recommendation for its use in patients with isolated TBI without anticoagulation therapy [67]. Administration of 


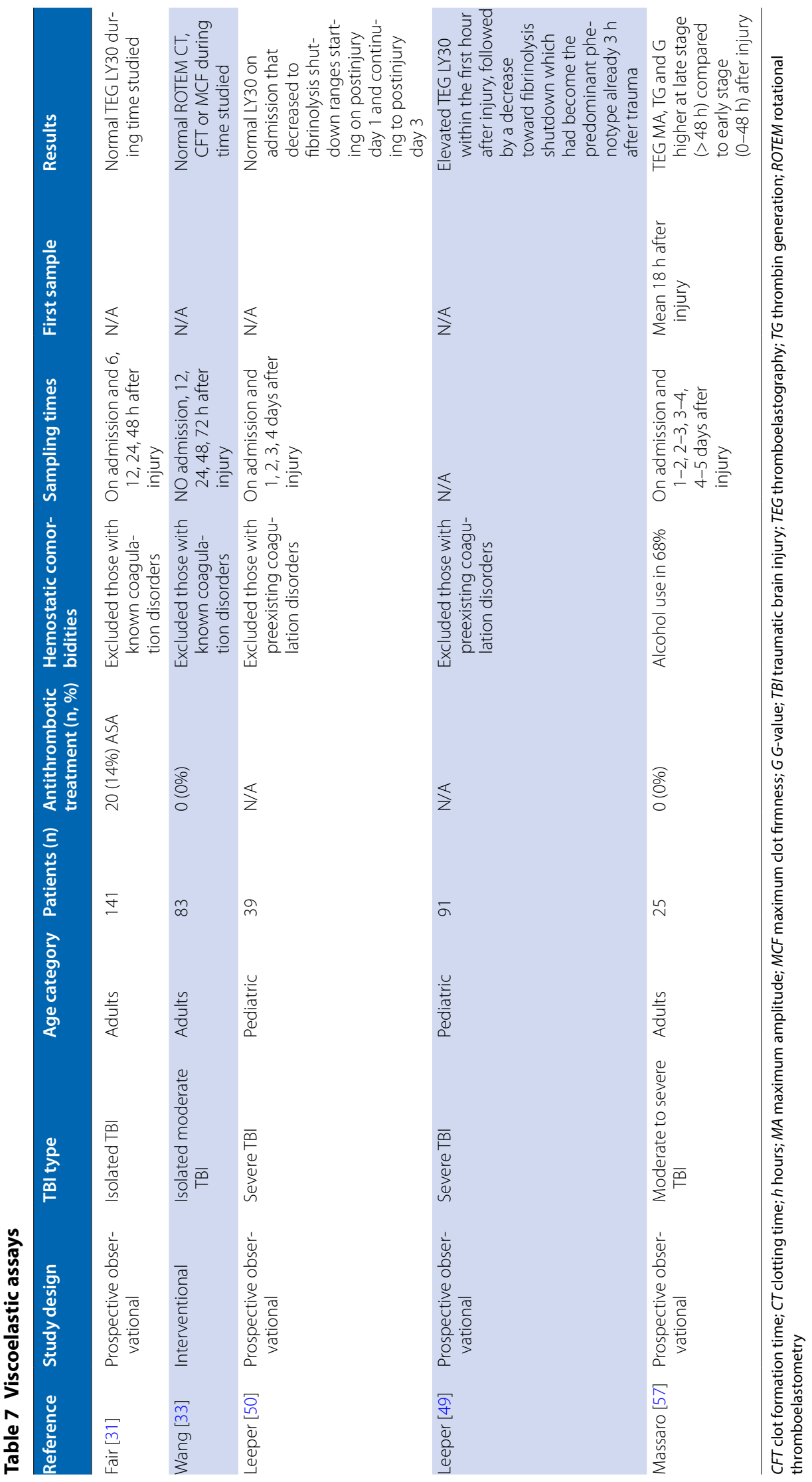




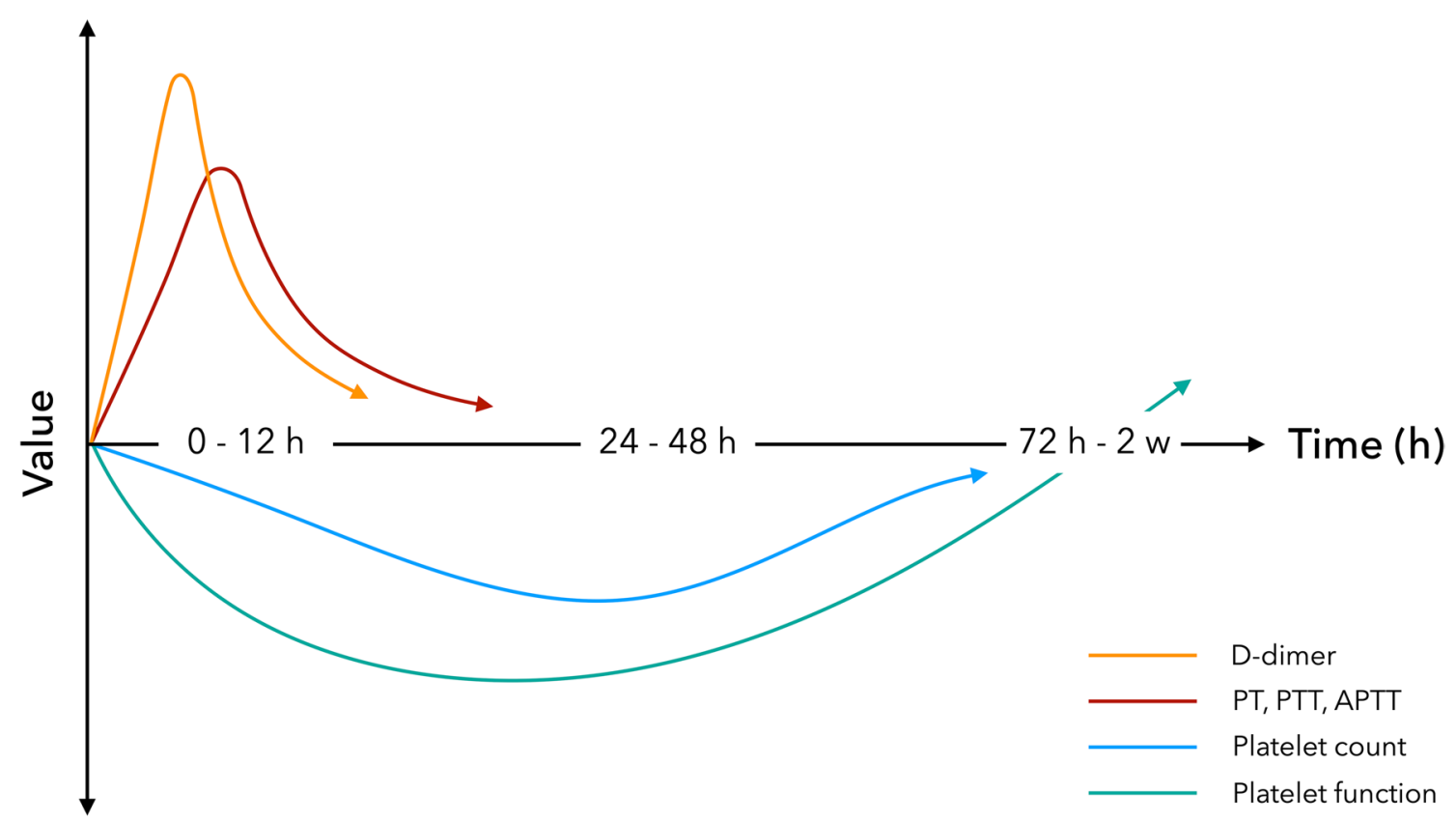

Fig. 2 Conceptual figure of the time course of hemostatic disruptions after traumatic brain injury

recombinant FVIIa has also been associated with reduced hemorrhage progression in TBI, albeit with a higher rate of thrombosis, but the effect size was small and the benefit of routine recombinant FVIIa remains unclear [68]. Thus, there is a sound theoretical basis for the belief that consumption of clotting factors contributes to lesion progression in TBI, but there are yet no evidence-based treatment options to prevent this.

\section{Fibrinolysis}

Fibrinolysis is usually assessed using D-dimer and, to a certain extent, viscoelastic assays. Some studies also use $\mathrm{t}-\mathrm{PA}$, which stimulates conversion of plasminogen to plasmin, as well as PAI-1, an inhibitor of t-PA [69]. We observed an increase in D-dimer following TBI $[19,23$, $26,27,33,35,40,41,43-47]$, with peak levels seen during the first $6 \mathrm{~h}$ after injury $[19,23,40]$. This shows that TBI is followed by an early increase in fibrinolytic activity, which also seems to be proportional to injury severity [19]. This is supported by the observation that PAI-1 and $\mathrm{t}$-PA are increased during the same time period [23, 43, $46,48]$. However, only one study could verify this using viscoelastic assays during the first hour after injury [49]. This could mean that hyperfibrinolysis is only present within this short time interval, or be due to an arbitrary threshold for hyperfibrinolysis [70] and LY30's relative lack of sensitivity to changes in fibrinolysis [23]. Highlighting this, a study of general trauma found that $90 \%$ of patients with hyperfibrinolysis on $\mathrm{D}$-dimer, t-PA and plasmin- $\alpha 2 \mathrm{AP}$ did not meet criteria based on TEM, leading the authors to conclude that TEM may be an unreliable measurement of endogenous fibrinolytic activity [71]. Thus, hyperfibrinolysis is evident in the acute phase following TBI, but it remains unclear exactly for how long it continues (Fig. 2).

\section{Clinical Implications}

It has been suggested that hyperfibrinolysis is a main driving force behind trauma-induced bleeding disorders in TBI, and can cause hemorrhage expansion via the degradation of coagulation factors, breakdown of the formed fibrin clot, and impairment of clot formation as a result of excessive generation of fibrin degradation products. Moreover, from a time-based standpoint, hyperfibrinolysis appears to occur when the risk of intracranial lesion progression is high [52]. A subgroup analysis from the CRASH-3 randomized trial found that administration of tranexamic acid (TXA) was associated with a reduction in 28-day head injury-related mortality if administered within $3 \mathrm{~h}$ to patients with mild-to-moderate isolated TBI [72]. This indicates that antifibrinolytic drugs can provide effective treatment. However, the CRASH-3 study protocol was modified, reducing the time from injury to randomization from 8 to $3 \mathrm{~h}$, and no treatment effect was seen in patients with severe TBI. Limiting the time window after TBI probably increased the chance that TXA was administered when hyperfibrinolysis actually took place. Based on the observations in this review, 
one would expect prehospital administration of TXA to be even more effective, a treatment option which has been assessed in a completed but not yet published trial (ClinicalTrials.gov Identifier: NCT01990768). Other antifibrinolytic drugs, such as aprotinin, epsilon-aminocaproic acid and aminomethylbenzoic acid, are all also theoretically sound options but have not been assessed in TBI. Thus, early hyperfibrinolysis appears to contribute to lesion progression, and there is evidence in support of antifibrinolytic treatment in a subgroup of TBI patients if administered early.

\section{Prothrombotic State}

TBI is also independently associated with an increased risk of thromboembolic complications that persist after index hospitalization [10-18, 73]. Most likely, initial hypocoagulability transitions to a subacute hypercoagulability phase. Recent evidence suggests that posttraumatic fibrinolytic shutdown is associated with a higher risk of thromboembolic events in TBI [74]. In the pediatric study by Leeper et al., fibrinolysis shutdown (as indicated by low TEG LY30 levels) was the predominant phenotype already $3 \mathrm{~h}$ after injury [49]. Similarly, in their study using TEM in adult patients with moderate-severe TBI, Massaro et al. identified a progressive and delayed hypercoagulable state that was more common $>48 \mathrm{~h}$, compared to $<48 \mathrm{~h}$, after injury [57]. With regard to platelet function, two studies found that multiplate levels increased above reference ranges 1-2 weeks following initial trauma $[29,37]$. Collectively, these results indicate a delayed prothrombotic state characterized by initial fibrinolysis shutdown, which appears within hours to days of injury, and later possible platelet hyperactivity. However, the time point at which a patient becomes phenotypically prothrombotic remains unclear, and will most likely be a combination of these factors countered by any residual coagulation cascade dysfunction and thrombocytopenia. These findings warrant particular consideration with regard to several unresolved clinical dilemmas in order to decrease the rates of VTEs and capillary microthrombi seen in vulnerable TBI patients, such as the timing of postinjury pharmacological thromboprophylaxis and resumption of oral anticoagulation therapy. However, more studies on long-term hemostatic disruptions after TBI are needed before any further conclusions can be drawn.

\section{Age Differences}

The three studies that included patients of all ages did not perform any analysis to differentiate between adult and pediatric populations $[32,42,45]$. In the four studies that focused exclusively on pediatric populations, posttraumatic elevations in D-dimer [44], PAI-1, t-PA [48] and
TEG LY30 [49, 50] were noted. Thus, pediatric patients seem to experience posttraumatic hyperfibrinolysis, but a direct comparison to adults is lacking. Moreover, to date, no studies have assessed whether pediatric patients undergo posttraumatic changes in platelet count, platelet function and coagulation cascade function as well.

\section{Systemic Versus Localized Hemostasis}

The primary contusion in TBI is the result of ruptured microvessels. In the penumbra and surrounding regions, molecular processes can then be activated leading to hemorrhagic progression or new lesions [75]. The addition of hemostatic disturbance contributes to lesion progression [76]. For all studies included in this review, the assumption has been made that hemostatic assays sampled from the systemic circulation are applicable to the brain vasculature as well. However, the complexity of the cerebral microvessel walls, and their differences in structure and function compared to extracranial vessels, might suggest that hemostatic response differs regionally [77]. In severe sepsis for example, certain organs have been found to be at a greater risk of thrombosis than others, indicating that hemostatic disruption might partly be a localized phenomenon [78]. With this said, there is still very little evidence that blood or plasma is altered in its passage through the brain, or that the brain environment alters blood components under normal conditions [79].

\section{Study Limitations}

There are some limitations to this study that should be mentioned. For one, TBI is heterogeneous and multifactorial, consisting of a mix of pathologic processes that can be active in different patients and in different regions of the brain. In addition, the methodological quality of the included studies reviews was variable, with many being observational cohort studies without control groups and variable numbers of participants. Studies also varied in terms of sampling frequency and follow-up time. Different cutoff levels and parameters were also used for the hemostatic assays, which makes standardization and interpretation difficult. We also only made use of a single search database to perform our systematic review, which could exclude potentially valuable articles [80]. However, we also screened the reference lists of the included studies and thus consider this risk to be minor. Despite its limitations, we believe that clinically helpful and valid conclusions can be drawn from this review, and will be useful in designing future studies and clinical practice guidelines.

\section{Conclusions and Future Directions}

Altered hemostasis, with early hemorrhagic progression and later thrombotic complications, is a 
substantial and ongoing challenge in the management of TBI. There is currently a lack of well-designed prospective trials reviewing the temporal trend in hemostatic disruption, making it difficult to identify windows of opportunity for potential treatment options. Moreover, most data underlying the initiation and progression of hemostatic disruption in TBI are speculative and not linked to causative data. Based on the results from this review, it appears that TBI is followed by both early and delayed hemostatic disturbance. The first hours after TBI are characterized by a derangement of the coagulation system, as a consequence of massive and systemic activation, and hyperfibrinolysis, both of which likely contribute to lesion progression. This is then followed by decreased platelet function and count, the clinical significance of which remains unclear. Thereafter, a poorly defined prothrombotic state emerges, which might be characterized by fibrinolysis shutdown and hyperactive platelets. In the clinical setting, only early administration of TXA has proved effective in reducing the risk of headinjury related mortality in a subgroup of TBI patients. Further studies aimed at analyzing the progress of hemostatic disruption following TBI are warranted. In particular, studies with high-frequency early sampling are warranted in order to characterize the cause behind intracranial lesion progression, as well as those with longer follow-up times in order to understand the delayed prothrombotic state. Studies using point-ofcare viscoelastic assays are also of particular interest, as they have the potential of providing real-time information in the clinical setting.

\section{Electronic supplementary material}

The online version of this article (https://doi.org/10.1007/s12028-020-01037-8) contains supplementary material, which is available to authorized users.

\begin{abstract}
Abbreviations
AA: Arachidonic acid; ADP: Adenosine diphosphate; AIS: Abbreviated injury scale; APTT: Activated partial thromboplastin time; ASPI: Aspirin; CFT: Clotting formation time; COL: Collagen; CT: Clotting time; F1 + 2: Prothrombin fragment 1+2; FFP: Fresh-frozen plasma; GCS: Glasgow coma scale; LY30: Lysis index 30; MA: Maximum amplitude; MCF: Maximum clot firmness; PAI-1: Plasminogen activator inhibitor-1; PCC: Prothrombin complex concentrate; PT: Prothrombin time; PTT: Partial thromboplastin time; t-PA: Tissue plasminogen activator; TAT: Thrombin antithrombin III complex; TBI: Traumatic brain injury; TEG: Thromboelastography; TEM: Thromboelastometry; TRAP: Thrombin receptor-activating peptide; TXA: Tranexamic acid.
\end{abstract}

\footnotetext{
Author details

1 Department of Neurosurgery, Karolinska University Hospital, Stockholm, Sweden. ${ }^{2}$ Department of Clinical Neuroscience, Karolinska Institutet, Bioclinicum J5:20, 17164 Solna, Stockholm, Sweden. ${ }^{3}$ Department of Neurology, Karolinska University Hospital, Stockholm, Sweden. ${ }^{4}$ Department for Trauma and Orthopedic Surgery, Cologne-Merheim Medical Center, University Witten/ Herdecke, Cologne, Germany. ${ }^{5}$ Institute for Research in Operative Medicine, University Witten/Herdecke, Cologne, Germany.
}

\section{Acknowledgements}

Open access funding provided by Karolinska Institute.

\section{Funding}

No funding was received for this research project.

\section{Conflict of interest}

Marc Maegele has received honoraria for speaker's bureaus, participation in advisory board meetings and congress travel support from IL-Werfen/TEM International and Haemonetics. BMB has received speaker's fees from CSL Behring. All other authors declare no competing interests.

\section{Ethical Approval}

We confirm that authorship requirements have been met and the final manuscript was approved by all authors.

\section{Consent for Publication}

We confirm that this manuscript has not been published elsewhere and is not under consideration by another journal.

\section{Open Access}

This article is licensed under a Creative Commons Attribution 4.0 International License, which permits use, sharing, adaptation, distribution and reproduction in any medium or format, as long as you give appropriate credit to the original author(s) and the source, provide a link to the Creative Commons licence, and indicate if changes were made. The images or other third party material in this article are included in the article's Creative Commons licence, unless indicated otherwise in a credit line to the material. If material is not included in the article's Creative Commons licence and your intended use is not permitted by statutory regulation or exceeds the permitted use, you will need to obtain permission directly from the copyright holder. To view a copy of this licence, visit http://creativecommons.org/licenses/by/4.0/.

\section{Publisher's Note}

Springer Nature remains neutral with regard to jurisdictional claims in published maps and institutional affiliations.

Published online: 30 June 2020

\section{References}

1. Stocchetti N, Zanier ER. Chronic impact of traumatic brain injury on outcome and quality of life: a narrative review. Crit Care. 2016;20:1-10.

2. Maegele M, Schöchl H, Menovsky T, Maréchal H, Marklund N, Buki A, et al. Coagulopathy and haemorrhagic progression in traumatic brain injury: advances in mechanisms, diagnosis, and management. Lancet Neurol. 2017;16:630-77.

3. Harhangi BS, Kompanje EJO, Leebeek FWG, Maas AIR. Coagulation disorders after traumatic brain injury. Acta Neurochir (Wien). 2008;150:165-75.

4. Chang R, Cardenas JC, Wade CE, Holcomb JB. Advances in the understanding of trauma-induced coagulopathy. Blood. 2016:128:1043-9.

5. Herbert JP, Guillotte AR, Hammer RD, Scott LN. Coagulopathy in the setting of mild traumatic brain injury: Truths and consequences. Brain Sci. 2017;7:92.

6. Fletcher-Sandersjöö A, Maegele M, Bellander B-M. Does complementmediated hemostatic disturbance occur in traumatic brain injury? A literature review and observational study protocol. Int J Mol Sci. 2020;21:1596

7. Folkerson LE, Sloan D, Cotton BA, Holcomb JB, Tomasek JS, Wade CE. Predicting progressive hemorrhagic injury from isolated traumatic brain injury and coagulation. Surgery. 2015;158:655-61.

8. Zhang J, Zhang F, Dong JF. Coagulopathy induced by traumatic brain injury: systemic manifestation of a localized injury. Blood. 2018;131:2001-6.

9. Yuan Q, Sun YR, Wu XHX, Yu J, Li ZQ, Du ZY, et al. Coagulopathy in traumatic brain injury and its correlation with progressive hemorrhagic injury: a systematic review and meta-analysis. J Neurotrauma. 2016;33:1279-91. 
10. Skrifvars MB, Bailey M, Presneill J, French C, Nichol A, Little L, et al. Venous thromboembolic events in critically ill traumatic brain injury patients. Intensive Care Med. 2017:43:419-28.

11. Strollo BP, Bennett GJ, Chopko MS, Guo WA. Timing of venous thromboembolism chemoprophylaxis after traumatic brain injury. J Crit Care. 2018;43:75-80.

12. Glass NE, Vadlamani A, Hwang F, Sifri ZC, Kunac A, Bonne S, et al. Bleeding and thromboembolism after TBI in the elderly: a real conundrum. J Surg Res. 2019:235:615-20.

13. Hachem LD, Mansouri A, Scales DC, Geerts W, Pirouzmand F. Anticoagulant prophylaxis against venous thromboembolism following severe traumatic brain injury: a prospective observational study and systematic review of the literature. Clin Neurol Neurosurg. 2018;175:68-73.

14. Albrecht JS, Liu X, Smith GS, Baumgarten M, Rattinger GB, Gambert SR, et al. Stroke incidence following traumatic brain injury in older adults HHS public access. J Head Trauma Rehabil. 2015;30:62-7.

15. Kowalski RG, Haarbauer-Krupa JK, Bell JM, Corrigan JD, Hammond FM, Torbey MT, et al. Acute ischemic stroke after moderate to severe traumatic brain injury: incidence and impact on outcome. Stroke. 2017:48:1802-9.

16. Liu SW, Huang LC, Chung WF, Chang HK, Wu JC, Chen LF, et al. Increased risk of stroke in patients of concussion: A nationwide cohort study. Int J Environ Res Public Health. 2017;14:230.

17. Eric Nyam TT, Ho CH, Chio CC, Lim SW, Wang JJ, Chang CH, et al. Traumatic brain injury increases the risk of major adverse cardiovascular and cerebrovascular events: a 13-year, population-based study. World Neurosurg. 2019;122:e740-e53.

18. McFarlane TD, Love J, Hanley S, Dixon BE, Hammond FM. Increased risk of stroke among young adults with serious traumatic brain injury. J Head Trauma Rehabil. 2019;1.

19. Nakae R, Takayama Y, Kuwamoto K, Naoe Y, Sato H, Yokota H. Time course of coagulation and fibrinolytic parameters in patients with traumatic brain injury. J Neurotrauma. 2016;33:688-95.

20. Nakae R, Yokobori S, Takayama Y, Kuwamoto K, Naoe Y, Yokota H. Agerelated differences in fibrinolytic parameters in patients with acute traumatic brain injury. Surg Neurol Int 2017;8.

21. Lustenberger T, Talving P, Kobayashi L, Inaba K, Lam L, Plurad D, et al. Time course of coagulopathy in isolated severe traumatic brain injury. Injury. 2010;41:924-8.

22. Nekludov M, Bellander B-MM, Blombäck M, Wallen HN, Blomback M, Wallen HN. Platelet dysfunction in patients with severe traumatic brain injury. J Neurotrauma. 2007:24:1699-706.

23. Fair K, Farrell D, McCully B, Rick E, Dewey EN, Hilliard C, et al. Fibrinolytic activation in patients with progressive intracranial hemorrhage after traumatic brain injury. New York: Mary Ann Liebert Inc; 2019.

24. Briggs A, Gates JD, Kaufman RM, Calahan C, Gormley WB, Havens JM. Platelet dysfunction and platelet transfusion in traumatic brain injury. J Surg Res. 2015;193:802-6.

25. Wang H, Cao H, Zhang X, Ge L, Bie L. The effect of hypertonic saline and mannitol on coagulation in moderate traumatic brain injury patients. Am J Emerg Med. 2017:35:1404-7.

26. Scherer RU, Spangenberg P. Procoagulant activity in patients with isolated severe head trauma. Crit Care Med. 1998:26:149-56.

27. Grenander B, Bredbacka S, Rydvall A, Ároch R, Edner G, Koskinen LOD, et al. Antithrombin treatment in patients with traumatic brain injury: a pilot study. J Neurosurg Anesthesiol. 2001;13:49-56.

28. Bredbacka S, Edner G. Soluble fibrin and D-dimer as detectors of hypercoagulability in patients with isolated brain trauma. J Neurosurg Anesthesiol. 1994;6:75-82.

29. Kutcher ME, Redick BJ, McCreery RC, Crane IM, Greenberg MD, Cachola LM, et al. Characterization of platelet dysfunction after trauma. J Trauma Acute Care Surg. 2012;73:13-9.

30. Vecht CJ, Sibinga CT, Minderhoud JM. Disseminated intravascular coagulation and head injury. J Neurol Neurosurg Psychiatry. 1975;38:567-71.

31. Auer L. Disturbances of the coagulatory system in patients with severe cerebral trauma. I. Acta Neurochir. 1978:43:51-9.

32. Carrick M, Tyroch A, Youens C, Handley T. Subsequent development of thrombocytopenia and coagulopathy in moderate and severe head injury: support for serial laboratory examination. J Trauma. 2005;58:725-9.

33. Hulka F, Mullins RJ, Frank EH. Blunt brain injury activates the coagulation process. Arch Surg. 1996;131:923-7 (discussion 927-8)
34. Engström M, Romner B, Schalén W, Reinstrup P. Thrombocytopenia predicts progressive hemorrhage after head trauma. J Neurotrauma. 2005:22:291-6.

35. Touho H, Hirakawa K, Hino A, Karasawa J, Ohno Y. Relationship between abnormalities of coagulation and fibrinolysis and postoperative intracranial hemorrhage in head injury. Neurosurgery. 1986;19:523-31.

36. Guillotte AR, Herbert JP, Madsen R, Hammer RD, Litofsky NS. Effects of platelet dysfunction and platelet transfusion on outcomes in traumatic brain injury patients. Brain Inj. 2018:32:1849-57.

37. Lindblad C, Thelin EP, Nekludov M, Frostell A, Nelson DW, Svensson $\mathrm{M}$, et al. Assessment of platelet function in traumatic brain injury-A retrospective observational study in the neuro-critical care setting. Front Neurol. 2018:9:15.

38. Vecht CJ, Minderhoud JM, Sibinga CT. Platelet aggregability in relation to impaired consciousness after head injury. J Clin Pathol. 1975;28:814-20

39. Halpern CH, Reilly PM, Turtz AR, Stein SC. Traumatic coagulopathy: the effect of brain injury. J Neurotrauma. 2008;25:997-1001.

40. Pahatouridis D, Alexiou GA, Zigouris A, Mihos E, Drosos D, Voulgaris $S$. Brain injury coagulopathy in moderate head injury. The role of early administration of low molecular weight heparin. 2010;

41. Nekludov M, Antovic J, Bredbacka S, Blombäck M. Coagulation abnormalities associated with severe isolated traumatic brain injury: cerebral arterio-venous differences in coagulation and inflammatory markers. J Neurotrauma. 2007:24:174-80.

42. Sørensen JV, Jensen HP, Rahr HB, Borris LC, Lassen MR, Fedders O, et al. Haemostatic activation in patients with head injury with and without simultaneous multiple trauma. Scand J Clin Lab Invest. 2009;53:659-65.

43. Gando S, Nanzaki S, Kemmotsu O. Coagulofibrinolytic changes after isolated head injury are not different from those in trauma patients without head injury. J Trauma. 1999;46:1070-6 (discussion 1076-7).

44. Foaud HMA, Labib JR, Metwally HG, El-Twab KMA. Plasma D-dimer as a prognostic marker in ICU admitted Egyptian children with traumatic brain injury. J Clin Diagn Res. 2014;8:PC01-6.

45. Suehiro E, Fujiyama Y, Kiyohira M, Motoki Y, Nojima J, Suzuki M. Probability of soluble tissue factor release lead to the elevation of d-dimer as a biomarker for traumatic brain injury. Neurol Med Chir (Tokyo). 2019;59:63-7.

46. Karri J, Cardenas JC, Matijevic N, Wang YW, Choi S, Zhu L, et al. Early fibrinolysis associated with hemorrhagic progression following traumatic brain injury. Shock. 2017:48:644-50.

47. Defazio M V., Rammo RA, Robles JR, Bramlett HM, Dietrich WD, Bullock MR. The potential utility of blood-derived biochemical markers as indicators of early clinical trends following severe traumatic brain injury. World Neurosurg. 2014. p. 151-8.

48. Becker S, Schneider W, Kreuz W, Jacobi G, Scharrer I, Nowak-Göttl U. Post-trauma coagulation and fibrinolysis in children suffering from severe cerebro-cranial trauma. Eur J Pediatr. 1999;158(Suppl 3):S197-202.

49. Leeper CM, Strotmeyer SJ, Neal MD, Gaines BA. Window of opportunity to mitigate trauma-induced coagulopathy: fibrinolysis shutdown not prevalent until 1 hour post-injury. Ann Surg. 2019;270:528-34.

50. Leeper CM, Neal MD, McKenna CJ, Gaines BA. Trending fibrinolytic dysregulation: fibrinolysis shutdown in the days after injury is associated with poor outcome in severely injured children. Ann Surg. 2017;266:508-15.

51. Greuters S, van den Berg A, Franschman G, Viersen VA, Beishuizen A Peerdeman SM, et al. Acute and delayed mild coagulopathy are related to outcome in patients with isolated traumatic brain injury. Crit Care. 2011;15:R2

52. Homnick A, Sifri Z, Yonclas P, Mohr A, Livingston D. The temporal course of intracranial haemorrhage progression: How long is observation necessary? Injury. 2012;43:2122-5.

53. Tynngård N, Lindahl TL, Ramström S. Assays of different aspects of haemostasis - what do they measure? Thromb J 2015.

54. Vulliamy P, Kornblith LZ, Kutcher ME, Cohen MJ, Brohi K, Neal MD. Alterations in platelet behavior after major trauma: adaptive or maladaptive? Platelets 2020. p. 1-10.

55. Jacoby RC, Owings JT, Holmes J, Battistella FD, Gosselin RC, Paglieroni TG. Platelet activation and function after trauma. JTrauma. 2001;51:639-47.

56. Verni CC, Davila A, Balian S, Sims CA, Diamond SL. Platelet dysfunction during trauma involves diverse signaling pathways and an inhibitory activity in patient-derived plasma. J Trauma Acute Care Surg. 2019;86:250-9. 
57. Massaro AM, Doerfler S, Nawalinski K, Michel B, Driscoll N, Ju C, et al. Thromboelastography defines late hypercoagulability after TBI: a pilot study. Neurocrit Care. 2015;22:45-51.

58. Stein SC, Graham DI, Chen X-H, Smith DH. Association between intravascular microthrombosis and cerebral ischemia in traumatic brain injury. Neurosurgery. 2004;54:687-91 (discussion 691)

59. Kurland D, Hong C, Aarabi B, Gerzanich V, Simard JM. Hemorrhagic progression of a contusion after traumatic brain injury: a review. New York: Mary Ann Liebert, Inc: 2012. p. 19-31.

60. Furay E, Daley M, Teixeira PG, Coopwood TB, Aydelotte JD, Malesa N, et al. Goal-directed platelet transfusions correct platelet dysfunction and may improve survival in patients with severe traumatic brain injury. J Trauma Acute Care Surg. 2018;85:881-7.

61. Kim DY, O'Leary M, Nguyen A, Kaji A, Bricker S, Neville A, et al. The effect of platelet and desmopressin administration on early radiographic progression of traumatic intracranial hemorrhage. J Neurotrauma. 2015;32:1815-21.

62. Furay EJ, Daley MJ, Satarasinghe P, Lara S, Aydelotte JD, Teixeira PG, et al. Desmopressin is a transfusion sparing option to reverse platelet dysfunction in patients with severe traumatic brain injury. J Trauma Acute Care Surg. 2020;88:80-6.

63. Wada T, Gando S, Maekaw K, Katabami K, Sageshima H, Hayakawa M, et al. Disseminated intravascular coagulation with increased fibrinolysis during the early phase of isolated traumatic brain injury. Crit Care. 2017;21:219.

64. Duguid J, O'Shaughnessy DF, Atterbury C, Maggs PB, Murphy M, Thomas $D$, et al. Guidelines for the use of fresh-frozen plasma, cryoprecipitate and cryosupernatant. Br. J. Haematol. 2004. p. 11-28.

65. Chang R, Folkerson LE, Sloan D, Tomasek JS, Kitagawa RS, Choi HA, et al. Early plasma transfusion is associated with improved survival after isolated traumatic brain injury in patients with multifocal intracranial hemorrhage. Surgery. 2017;161:538-45.

66. Joseph B, Amini A, Friese RS, Houdek M, Hays D, Kulvatunyou N, et al. Factor IX complex for the correction of traumatic coagulopathy. J Trauma Acute Care Surg. 2012. p. 828-34.

67. Ferreira J, Delossantos M. The clinical use of prothrombin complex concentrate. J Emerg Med. 2013;44:1201-10.

68. Narayan RK, Maas AIR, Marshall LF, Servadei F, Skolnick BE, Tillinger MN Recombinant factor viia in traumatic intracerebral hemorrhage: Results of a dose-escalation clinical trial. Neurosurgery. 2008;62:776-86.
69. Longstaff $C$. Measuring fibrinolysis: from research to routine diagnostic assays. J Thromb Haemost 2018. p. 652-62.

70. Ramos CR, Moore EE, Manco-Johnson ML, Silliman CC, Chapman MC, Banerjee $A$. The incidence and magnitude of fibrinolytic activation in trauma patients: a rebuttal. J Thromb Haemost 2013; p. 1435-7.

71. Raza I, Davenport R, Rourke C, Platton S, Manson J, Spoors C, et al. The incidence and magnitude of fibrinolytic activation in trauma patients. J Thromb Haemost. 2013;11:307-14.

72. CRASH-3 trial collaborators. Effects of tranexamic acid on death, disability, vascular occlusive events and other morbidities in patients with acute traumatic brain injury (CRASH-3): a randomised, placebo-controlled trial. Lancet 2019;394:1713-23.

73. Olufajo OA, Yorkgitis BK, Cooper Z, Rios-Diaz A, Metcalfe D, Havens JM, et al. How long should we fear? Long-term risk of venous thromboembolism in patients with traumatic brain injury. J Trauma Acute Care Surg. Lippincott Williams and Wilkins; 2016. p. 71-7.

74. Meizoso JP, Karcutskie CA, Ray JJ, Namias N, Schulman Cl, Proctor KG. Persistent fibrinolysis shutdown is associated with increased mortality in severely injured trauma patients. J Am Coll Surg. 2017;224:575-82.

75. Hay JR, Johnson VE, Young AMH, Smith DH, Stewart W. Blood-brain barrier disruption is an early event that may persist for many years after traumatic brain injury in humans. J Neuropathol Exp Neurol Oxford Academic. 2015;74:1147-57.

76. Zhang D, Gong S, Jin H, Wang J, Sheng P, Zou W, et al. Coagulation parameters and risk of progressive hemorrhagic injury after traumatic brain injury: a systematic review and meta-analysis. Biomed Res Int. 2015;2015:261825

77. Spatz M, Micic D, Mrsulja BB, Klatzo I. Cerebral microvessels as mediators of cerebral transport. Adv Neurol. 1978;20:189-96.

78. Levi M, Van Der Poll T, Schultz M. Systemic versus localized coagulation activation contributing to organ failure in critically ill patients. Semin Immunopathol Springer; 2012. p. 167-79.

79. Del Zoppo GJ, Izawa Y, Hawkins BT. Hemostasis and alterations of the central nervous system. Semin Thromb Hemost. 2013;39:856-75.

80. Rollin L, Darmoni S, Caillard JF, Gehanno JF. Searching for high-quality articles about intervention studies in occupational health-What is really missed when using only the Medline database? Scand J Work Environ Heal. 2010;36:484-7. 